
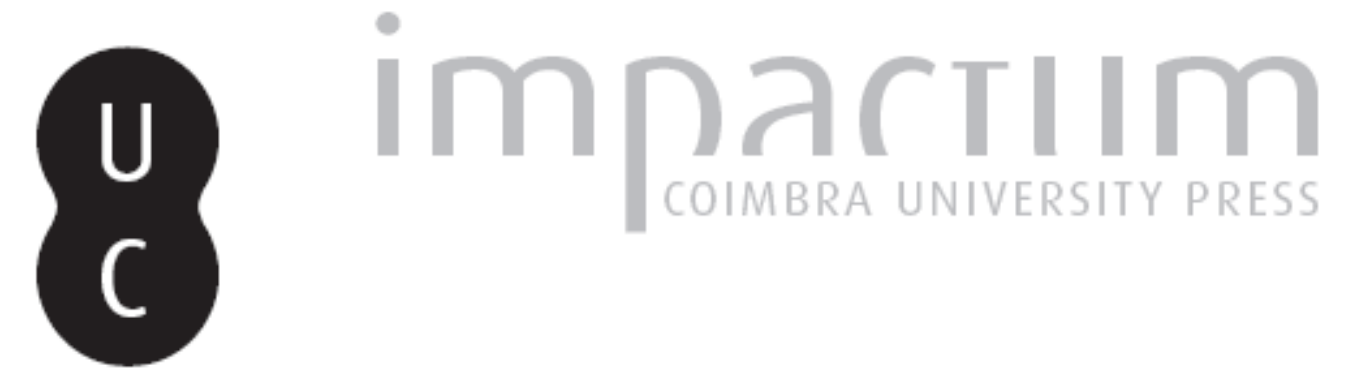

\title{
Um aceso silêncio: a poesia de Cesare Pavese e suas traduções em língua portuguesa
}

\author{
Autor(es): $\quad$ Vasconcelos, José Manuel de \\ Publicado por: Imprensa da Universidade de Coimbra \\ URL \\ persistente: \\ URI:http://hdl.handle.net/10316.2/42494 \\ DOI: \\ DOI:https://doi.org/10.14195/0870-8584_7_1
}

Accessed : $\quad$ 26-Apr-2023 10:37:17

A navegação consulta e descarregamento dos títulos inseridos nas Bibliotecas Digitais UC Digitalis, UC Pombalina e UC Impactum, pressupõem a aceitação plena e sem reservas dos Termos e Condições de Uso destas Bibliotecas Digitais, disponíveis em https://digitalis.uc.pt/pt-pt/termos.

Conforme exposto nos referidos Termos e Condições de Uso, o descarregamento de títulos de acesso restrito requer uma licença válida de autorização devendo o utilizador aceder ao(s) documento(s) a partir de um endereço de IP da instituição detentora da supramencionada licença.

Ao utilizador é apenas permitido o descarregamento para uso pessoal, pelo que o emprego do(s) título(s) descarregado(s) para outro fim, designadamente comercial, carece de autorização do respetivo autor ou editor da obra.

Na medida em que todas as obras da UC Digitalis se encontram protegidas pelo Código do Direito de Autor e Direitos Conexos e demais legislação aplicável, toda a cópia, parcial ou total, deste documento, nos casos em que é legalmente admitida, deverá conter ou fazer-se acompanhar por este aviso.

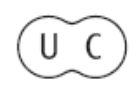




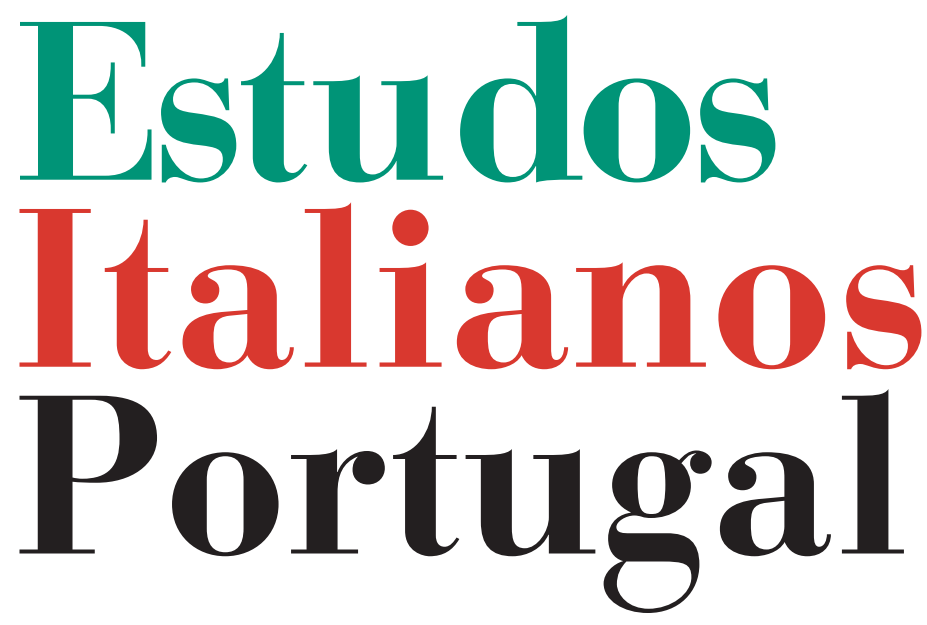

Instituto

Italiano

de Cultura

de Lisboa

Nova Série

$\mathbf{N}^{\mathbf{0}} 7$

2012 


\section{UM ACESO SILÊNCIO.A POESIA DE CESARE PAVESE E SUAS TRADUÇÕES EM LÍNGUA PORTUGUESA}

José Manuel de Vasconcelos*

A João Barrento

Un acceso silenzio

brucerà la campagna

come i falò la sera

Pavese

A obra de Cesare Pavese teve em Portugal uma difusão de que poucos autores estrangeiros se poderão gabar. É certo que um número significativo de importantes romances e colectâneas de novelas e contos da literatura italiana foram traduzidos para a nossa língua, ao longo de várias décadas, em particular nas décadas de cinquenta e sessenta do século passado. Mas o autor piemontês foi, ao lado de Pratolini, Vittorini e Moravia, um dos que mais atenção mereceu por parte dos editores portugueses, tendo praticamente toda a sua obra em prosa narrativa sido traduzida nesses anos, em alguns casos com novas traduções em anos mais recentes. Com a poesia as coisas não se passaram da mesma maneira, já que, apesar de não ser muito longa (essencialmente constituída por três recolhas de poemas ${ }^{1}$ ), só em 1997 foi publi-

* Poeta, ensaísta e tradutor, tem colaboração crítica e ensaística nas principais revistas literárias portuguesas. Ao seu último livro de poemas, $A$ mão na água que corre, foi recentemente atribuído o Prémio de Poesia da Sociedade Portuguesa de Autores. Traduziu, entre outros, Lorca, Montale, Saba, e os futuristas italianos. É colaborador do "Osservatorio Permanente Sugli Studi Pavesiani Nel Mondo"

${ }^{1}$ Tais recolhas são: Lavorare stanca, publicada pela primeira vez em Janeiro de 1936, em Florença, pelas Edizioni di Solaria, ligadas à famosa revista florentina, composta por apenas 45 poemas. A segunda edição, publicada em Turim, pela Einaudi, em 1943 (nuova edizione aumentata), contém já 70 poemas. A edição organizada por Italo Calvino acrescenta a esta obra inicial vários poemas inéditos. Ainda em vida de 
cado o volume Trabalhar cansa ${ }^{2}$, em edição bilingue, dando ao leitor português a possibilidade de conhecer grande parte do corpus estabelecido pela edição crítica que Italo Calvino preparou para a Einaudi, em $1962^{3}$, que, suponho, numa das suas várias reediçóes, tenha sido usada para a elaboração da edição portuguesa que referi. Cabe aqui assinalar, no entanto, sem pretender ser exaustivo (já que me podem ter escapado trabalhos surgidos em revistas ou jornais de menor visibilidade, dada a passagem do tempo), traduçôes anteriores de alguns poemas, como sejam as que Jorge de Sena nos dá de "Tu sei come una terra", "Sei la terra e sei la morte", e "Verrà la morte..." ; a que David Mourão-Ferreira fez com o título de "Virá a Morte..." ; as que Pedro da Silveira incluiu na sua Mesa de amigos 6 , ou seja, "Os Mares do Sul", "A Noite" e "The Cats Will Know", ou a tradução de Ernesto Sampaio

Pavese, foi publicado o conjunto intitulado La terra e la morte, em Pádua, em 1947, no número XXI da revista Le tre Venezie, dirigida por Antonio Barolini. Estes poemas, escritos em 1945, estão muito distantes da produção poética anterior de Pavese, e passaram a integrar a obra póstuma Verrà la morte e avrà $i$ tuoi occhi, publicada pela Einaudi, em 1951, acrescentando-se aos 10 poemas inéditos (8 escritos em italiano e 2 em inglês) para Constance Dowling, datados de Março e Abril de 1950, e que foram descobertos, após o suicídio de Pavese, numa pasta do escritor, na editora Einaudi, onde trabalhava. A edição de Calvino não inclui todos os poemas de Pavese, tendo deixado os poemas da adolescência e da juventude para uma juvenilia a publicar. Em 1964 o famoso editor milanês Vanni Scheiwiller publicou Otto poesie inedite e quatro lettere a un'amica (1928-1929), con uno scritto di Enrico Emanuelli, e em 1970 a revista Strumenti Critici, de Turim, publicou "Due poesie inedite".

2 Trabalhar cansa, tradução e introdução de Carlos Leite, Lisboa, Cotovia, 1997, $1 .^{a}$ reimpressão, 2008.

${ }^{3}$ Poesie edite e inedite, a cura di Italo Calvino, Torino, Einaudi, 1962.

${ }^{4}$ Poesia do século XX (De Thomas Hardy a C.V. Cattaneo), antologia, tradução, prefácio e notas de Jorge de Sena, Porto, Editorial Inova, 1978, pp. 441-442.

${ }^{5}$ Vozes da poesia europeia III, traduções de David Mourão-Ferreira, Colóquio Letras, 165, Setembro-Dezembro de 2003, Lisboa, Fundação Calouste Gulbenkian, 2003, p. 206.

${ }^{6}$ Mesa de amigos, versões de poesia, colecção Gaivota, Angra do Heroísmo, Direcção Regional dos Assuntos Culturais, Secretaria Regional da Educação e Cultura, 1986, pp. 178-182. Reedição, Lisboa, Assírio \& Alvim, 2002, pp. 238-244. 
do poema "Paternidade" sua dimensão antológica, $O$ vício absurdo ${ }^{8}$, conjunto de poemas escolhidos, traduzidos e prefaciados por Rui Caeiro, em 1990. Nos casos que referi, de traduçóes de alguns poemas avulsos, verificamos que foram traduzidos os que talvez sejam os dois mais famosos de Pavese, "I mari del Sud" e "Verrà la morte...", o primeiro, poema inicial de Lavorare stanca, importantíssimo pela sua natureza matricial relativamente à poética do autor, perfeito exemplo das concepçôes iniciais de Pavese acerca da poesia e até, mais genericamente, da escrita literária; o segundo, verdadeiro emblema da colectânea epónima, habitada por um dramatismo que realiza a previsão do autor quando escreveu: "virá um momento em que faremos poemas cansados, vazios de promessas, aqueles que justamente assinalarão o fim da aventura"' .

Lavorare stanca, publicado em 1936, marca o início do período intenso, mas breve, da produção literária relevante de Pavese ${ }^{10}$, que termina com o romance La luna e i falò, publicado em 1950, menos de três meses antes da sua morte por suicídio. Cerca de quinze anos de vida e de literatura, que as anotaçóes do diário póstumo Il mestiere di vivere (também traduzido para português) reflectem de modo quase sempre indirecto, fazendo lampejar as tensóes de uma consciência fustigada pela dúvida, dominada pelo pessimismo, reflectindo um sofrimento que não cessa de procurar as suas razóes mais profundas, mas que visita também as sombras da cria-

${ }^{7}$ A rosa do mundo, 2001 poemas para o futuro, Lisboa, Assírio \& Alvim, 2001, pp. 1486-1487.

${ }^{8}$ O vício absurdo, selecção, prefácio e tradução de Rui Caeiro, Lisboa, \& etc, 1990.

9 "A propósito de certas poesias ainda não escritas", Trabalhar cansa, p. 301.

${ }^{10}$ O poema "I mari del Sud", que Pavese considerava o seu primeiro poema, foi escrito de 7 a 14 de Setembro de 1930. Para além de traduçôes várias (Moby Dick de Melville, Sherwood Anderson, John dos Passos, Joyce), antes da publicação de Lavorare stanca, Pavese concluiu, em 1932, a redacção de Ciao Masino, cuja importância seminal tem sido posta em relevo pela crítica pavesiana. 
ção artística, num registo de amargura distante e fria, em que a obsessão da auto-aniquilação vai adquirindo a espessura de uma certeza cega: "Para dizer a verdade, durante estes anos a intenção construtiva, mais do que nos novos poemas, exprime-se nas meditações diarísticas que os acompanham e, no fim, sufocaram"11.

A poesia, em Pavese, tal como o diário, vai-se gradualmente despenhando no vazio da morte, afirmando uma trágica solidão. A negatividade que atravessa Il mestiere di vivere, tem a sua conclusão lógica na anotação final, que anuncia o gesto derradeiro e lhe confere a força e a dimensão de um selo, na medida em que, com o suicídio, o que no diário nos aparece como discurso, atinge o seu pleno significado e uma amplitude que ultrapassa largamente os limites do literário, por ser fruto de uma maturação reflexiva sobre os limites da literatura e da vida, implicando uma aguda consciência da transformação e a aceitação do saber feito da inevitabilidade do inelutável. O conceito de maturação é, aliás, decisivo para a compreensão de Pavese, da obra, do homem. "Ripeness is all", escreveu na dedicatória do romance La luna e $i$ falò a Constance Dowling, derradeira frustração sentimental que terá tido um peso determinante no seu suicídio. A frase, extraída do King Lear, de Shakespeare, surge, em citação mais extensa, no breve ensaio intitulado precisamente L'arte di maturare: "man must endure/his going hence e'en as his coming hither/Ripeness is all." ${ }^{2}$, como declaração de conformidade, de conciliação.

Pavese estabelece, logo no rosto do diário, uma ligação com o seu texto de reflexão metapoética intitulado Il mestiere di poeta, de 1934, que passou a estar integrado na colectânea Lavorare stanca, numa declaração de claro paralelismo entre os dois ofícios ou artes, a de escrever e a de viver. As

\footnotetext{
${ }^{11} \mathrm{Ib} ., \mathrm{p} .307$.

12 "Larte di maturare", Letteratura americana e altri saggi, Torino, Einaudi, 1990, p. 330.
} 
reflexões sobre a natureza e o papel da poesia, bem como sobre os problemas da criação literária em geral, abundam em todo o diário, sendo mais constantes e intensos nos primeiros anos, certamente como eco das dificuldades e questôes que o autor colocou a si próprio ao compor Lavorare stanca. A concepção de poesia que preside a esse livro tem como centro a ideia de imagem-narrativa, à qual Pavese se refere nestes termos: "Falo de uma situação sugestiva: de núcleos, de sangue, de complexos rítmicos. E digo que cada núcleo é uma imagem-narrativa" ${ }^{13}$. A prática poética de $\mathrm{Pa}-$ vese, por altura destas reflexóes, traduz-se em poemas extensos, em que o pendor narrativo é notório e a metaforização muito reduzida, lembrando bastante os que compóem Spoon River Anthology, de Edgar Lee Masters, obra muito apreciada por Pavese, várias vezes referida ao longo dos seus escritos ensaísticos, e cuja tradução para italiano ele próprio promoveu, incentivando Fernanda Pivano, sua amiga próxima, a fazê-la. Pavese tinha de facto uma grande admiração pela ficção poética construída pelo escritor norte-americano, pela sua linguagem coloquial, retoricamente descarnada, e sobretudo pela edificação de um lugar e de um tempo mítico-poético, em muitos aspectos semelhante ao que ele próprio anima na sua obra poética e narrativa, a partir do tempo da infância e da sua região natal. Acresce o conhecimento da literatura americana em geral, particularmente da obra de Walt Whitman, objecto da sua tese de licenciatura. O exemplo paradigmático da concepção inicial da poesia em Pavese, estaria, como o autor sustenta nas páginas do diário, no poema inaugural de Lavorare stanca, "I Mari del Sud". A poesia, para Pavese, era o resultado das projecçóes da sensibilidade actual na moldura fundadora, matricial, a que chama mito. Palavra que, para ele, corresponde a "essa imagem estática interior, embrionária, cheia de possíveis desenvolvimentos,

\footnotetext{
${ }^{13}$ Cesare Pavese, Il mestiere di vivere, terza edizione, Torino, Einaudi, 1958, p. 31.
} 
que está na origem de toda a criação poética"14. De qualquer modo, ao caracterizar esta imagem nuclear que subjaz na fantasia do poeta, e a agita, Pavese demarca-se de um "lirismo de confidência e introspecção", vendo-a como um arquétipo fundador, componente da mundividência pessoal, reflectindo embora, à sua maneira, representações e visões de dimensão colectiva, o que não admirará num autor para quem Platão é uma das grandes referências do pensamento universal e a que não faltarão certamente influências de Jung: "O meu gosto ansiava confusamente por uma expressão essencial de factos essenciais, que não fosse aquela abstracção introspectiva habitual que se exprime numa linguagem alusiva, porque livresca, que com tanta frequência e tão gratuitamente é qualificada como essencial" 15 . Não estamos, assim, nem no campo de uma poesia intimista, nem no domínio de uma representação naturalista, embora uma leitura apressada dos poemas de Lavorare stanca, possa indiciar essa tendência. Mas também não se trata de uma poética que, um pouco à maneira das concepçôes de Mallarmé, entendesse a palavra e a linguagem na sua materialidade significante como o centro do fazer poético. Esse centro, para Pavese, parece estar no próprio homem, enquanto ser vivo produtor de significação ${ }^{16}$, enquanto utilizador de uma sensibilidade com raízes longínquas nesses primeiros tempos em que tudo afinal definitivamente se joga: “Tudo se resolverá numa iluminação acesa pelos vários pensamentos e pelas sensações interligadas" ${ }^{\prime 1}$. A poesia é, assim, um discurso do encontro, uma tradução do fantástico, do "selvático" (no sentido pavesiano do

${ }^{14}$ Cesare Pavese, "Il mito", La letteratura americana e altri saggi, p. 315.

15 "O ofício de poeta", Trabalhar cansa, p. 281.

${ }^{16}$ Expressando uma concepção muito semelhante, no contexto da narrativa, escreve Pavese no seu Diário: "[...] a narração não é feita de realismo psicológico nem de naturalismo, mas de um desenho autónomo de factos, criados segundo um estilo que é a realidade de quem narra, único personagem insubstituível”, Il mestiere di vivere, p. 236.

${ }^{17}$ Ib., p. 64. 
termo $^{18}$ ), uma forma de conduzir a sensibilidade dentro das estruturas ou formas que desde cedo condicionam a nossa representação, o modo que cada um tem de representar o mundo. Estas formas não são, para Pavese, iguais em todos os homens, não estamos no âmbito de qualquer forma de apriorismo. Trata-se antes de criações pessoais, de construçōes próprias na apreensão da realidade, que se vão formando nos percursos dos primeiros tempos da existência, no embate inicial do eu com o mundo e da experiência que daí resulta. A escrita poética consiste numa paciente iluminação desses protótipos, na construção e dinamização das imagens-narrativa que configuram um impulso de retorno, de revisitação das coisas, como as define o nosso desejo, a nossa memória e os nossos receios; traduz-se num mergulho no vórtice do tempo, numa procura das fontes que esclarecem o nosso presente. Furio Jesi, grande estudioso dos mitos, afirma num ensaio sobre o escritor, a propósito de conceitos como solidão, evasão, fuga, retorno, que lhe são tão caros e nucleares: 'O retorno à aldeia' é sempre em Pavese uma $\kappa \alpha \tau \alpha \beta \alpha \sigma r \xi$ '19. Escrever é exumar, querer ver de novo, tornar possível a revisitação dos abismos que transportamos. Escreve-se contra o tempo, procura-se a fixidez longínqua, recriando o mundo: "O poeta, como é justo, aspira à imobilidade natural e sacral, ao silêncio, à morte; a transformar as paixões humanas em mitos polivalentes, eternos, intangíveis" ${ }^{\prime 2}$. No fundo, escre-

18 "O selvático que nos interessa não é a natureza, o mar, a floresta, mas o imprevisto no coração dos nossos companheiros homens", Cesare Pavese, "La selva", La letteratura americana e altri saggi, p. 315. O selvático é assim, para Pavese, o nefando, o impreciso, o desconhecido, aquilo que precisa de ser nomeado pelo esforço criador, para ser apaziguado, domesticado e, consequentemente, se tornar inócuo.

${ }^{19}$ Furio Jesi, Letteratura e mito, Torino, Giulio Einaudi Editore, 1968. Citado da tradução castelhana de António Pigrau Rodriguez, Literatura y mito, Barcelona, Barral, 1972, p. 163.

${ }^{20}$ Cesare Pavese, "La poetica del destino", La letteratura americana e altri saggi, p. 312. 
ver é iluminar o silêncio. Há na poética de Pavese uma valorização da imobilidade, uma aproximação desta ao sagrado, a uma zona indefinida, incorrupta, de pureza, que naturalmente será a infância, mas é também a morte, que, no seu abraço totalizador, se aproxima desse tempo branco, onde toda a inscrição pode (ainda) ter lugar. A morte, por ser o ignoto superlativo cuja imagem em nós tem de ser domesticada, seria, nesse sentido, o selvático supremo. O homem sabe que a morte é o único absoluto, a mais certa (ir)realidade. Para o poeta, para quem "a tensão para a poesia é dada no seu início pela ânsia de realidades espirituais desconhecidas, pressentidas como possíveis" ${ }^{21}$, a anulação de si enquanto suporte da imagem transcendental do mundo pode ser o acto poético supremo, aquele que aproxima realmente o esforço de unir a poesia e a vida. A frase final do diário, se, por um lado, é o culminar previsível das múltiplas alusões que Pavese ao longo das suas páginas faz ao suicídio como resposta a um sofrimento que "não serve para nada", é, por outro, manifestação ou exercício de uma soberana vontade de tomar as rédeas do próprio destino. Com tal frase, a vertigem da escrita autobiográfica é realçada, a sua espessura existencial ganha o relevo de uma rigorosa verdade, o eu torna-se central, paira nos escombros do diário como um Deus. O poeta (o homem) faz-se e desfaz-se, constrói-se e desconstrói-se enquanto imagem de si próprio, à procura duma "distância que é feita de coisas reais e perfeitas" 22 . A poesia confunde-se com essa procura, numa simbiose em que os dois oficios, o de viver e o de escrever, se tornam indissociáveis. A criação é uma espécie de pacto entre um mundo privado, no fim de contas intransmissível na sua plena complexidade, e o mundo partilhado, lugar de encontro possível com os outros. $\mathrm{Na}$ escrita poética esses dois espaços ganham a amplitude que a dimensão miticamente desfigurante da linguagem lhes pode trazer.

\footnotetext{
${ }^{21}$ Cesare Pavese, Il mestiere di vivere, p. 15.

${ }^{22} I b .$, p. 325.
} 
Consciente de que a encenação dos mitos pessoais, quando esses mitos radicam num referente comprovável (ainda que guindado à categoria de espaço e de tempo reinventado), como é o caso das suas paisagens natais da infância e adolescência, pode criar uma ilusão naturalista (e como se sabe, muitos críticos vêem no autor de Paesi tuoi, uma das figuras do neo-realismo), Pavese, seguindo a sombra criadora de Edgar Lee Masters, conclui que o método da poesia que preconiza é um compromisso entre a posição das personagens e a lógica imaginária da matéria que lhe dá substância: "Não narro apenas a sua essência e não narro apenas o meu fantasiar" $^{23}$. Será assim a poesia uma narrativa feita de imagens, ou será um jogo de imagens subjugadas a uma matriz, em que os aspectos éticos e rítmicos assumem um papel preponderante? Pavese coloca esta questão, sem lhe dar expressamente uma resposta. No entanto, em vários momentos do diário, é acentuada a inevitabilidade da sujeição da construção poética a esquemas míticos pré-fixados na consciência de cada um, a dimensão "encenada" do fazer poético, o seu aspecto dramático, no sentido em que o poema é confrontação, movimento resultante das vozes que o percorrem: "A força com que sente a vida, exprime-se não em imagens vivas, mas em entidades dramáticas e visionárias feitas de quotidianidade" ${ }^{24}$, escreve a propósito de Dostoievsky, mas a frase podia aplicar-se inteiramente à sua própria prática poética e narrativa. A demarcação de uma concepção introspectiva ou confessional da poesia, e a colocação do trabalho poético numa paisagem dialógica de encanto, aventura e mistério, cujos pressupostos de transcendência o aproximam da dimensão amorosa, é assim um aspecto central da reflexão pavesiana: "Amor e poesia estão misteriosamente ligados, porque ambos são desejo de expressão, de dizer, de comunicar" ${ }^{25}$. O sobressalto amoroso

\footnotetext{
${ }^{23}$ Ib., p. 64.

${ }^{24}$ Ib., p. 197.
} 
que, como ausência, e até impossibilidade, origina tantas das notas do diário, anda assim a par desse tremor a que a luz da maturação ajuda a dar sentido, e que engendra a poesia, mas também o desejo de morte, radicado ele também num sentimento de falta ou de incompletude. Da mesma forma que o impulso amoroso é mais intenso quando insatisfeito, também a poesia é um esforço de apreensão comparativo, de que provém a imagem, que é afinal a resultante de duas forças que partem de campos ontologicamente distintos: o mundo e a forma. Pavese, sempre centrado no entendimento da criação poética como esforço de apreensão da disparidade, chega à conclusão de que "Uma realidade somente se avalia quando se filtra numa outra. É por isso que a criança descobre o mundo através das transfigurações literárias, lendárias ou pelo menos, formais. É por isso que a "essência da poesia é a imagem" 26 . A imagem doméstica, por assim dizer, o que nos foge, o mistério do inapreensível, o que é permanente possibilidade, agilidade que desconcerta - o selvagem, numa palavra. Pavese vê na palavra poética o eco distante e sempre deformado de algo que se dá num halo de magia. E é enquanto força evocativa de uma realidade perdida no longínquo (do tempo, do espaço) que a palavra lhe interessa e forma as imagens nucleares do poema. A escrita poética tem, assim, algo de ritualístico, pela actualização que faz de um prodigioso que se pretende entender, pelo chamamento imitativo de uma ausência que é ferida aberta, "expressão essencial de factos essenciais". No centro da preocupação poética está, ao fim e ao cabo, um problema de comunicação, um esforço para romper o casulo em que a quotidianidade automática nos encerra. Também aí os ofícios pavesianos se encontram: o problema principal da existência é o da comunicação com os outros, nomeadamente a incomunicabilidade amorosa.

\footnotetext{
${ }^{25}$ Ib., p. 206.

${ }^{26} I b .$, p. 306.
} 
A amarga racionalidade pavesiana, feita de sarcasmo e de desencanto, a sua falta de fé, a sua vida eivada de desilusóes, que o levou a uma espécie de irremediável niilismo, fá-lo concluir que "sofrer não serve para nada", que todo o esforço é inútil. Tal como o poeta que "aspira à imobilidade natural e sacral, ao silêncio, à morte; a transformar as paixões humanas em mitos polivalentes, eternos, intangíveis" ${ }^{27}$, o homem aspira ao silêncio da natureza, a sua maturidade leva-o a saber e a aceitar que "Todos nós antes de nascermos estávamos mortos" 28 , que a morte é realidade sem tempo, verdade sempre actual, e que, portanto, "a única maneira de escapar ao abismo é olhá-lo, medi-lo, sondá-lo e descer por ele abaixo"29, sabendo (à semelhança dos ciclos da natureza) que a renovação é outro grande absoluto, a outra face da morte. Como não havia de sabê-lo quem, senhor do seu "ofício de viver", era confesso admirador de Platão e de Vico, e escreveu no seu diário este enigmático aforismo: "Tudo é repetição, revisitação, retorno. Com efeito, mesmo a primeira vez é já uma 'segunda vez"'30?

De tudo isto, e de muitos outros aspectos não abordados neste breve artigo, darão certamente conta as duas experiências tradutivas de maior extensão que referi, ao leitor que delas se aproximar: a de Rui Caeiro e a de Carlos Leite, ambas constituindo trabalhos de grande seriedade, com a fidelidade possível, tratando-se de poesia. Sabemos que Pavese não é, de entre os poetas italianos contemporâneos, dos mais difíceis de traduzir. Poesia e prosa não estavam no seu pensamento e na sua prática criativa separadas por nenhum fosso intransponível, antes pelo contrário. É dada sempre uma maior atenção às imagens mentais e à criação de atmosferas simbólicas do que aos aspectos formais do poema. O pró-

\footnotetext{
27 "La poetica del destino", La letteratura americana e altri saggi, p. 312.

${ }^{28}$ Il mestiere di vivere, p. 129.

${ }^{29} \mathrm{Ib}$., p. 46.

${ }^{30} \mathrm{Ib}$., p. 275.
} 
prio ritmo é, para Pavese, algo que existe antes do poema, espécie de "fantasma do significante", como lhe chamou Philippe Renard ${ }^{31}$, correspondendo ao modo próprio de o pensamento acontecer: "Sabia, naturalmente, que não existem metros tradicionais em sentido absoluto, mas que cada poeta refaz neles o ritmo interior da sua imaginação. E, um dia, dei comigo a murmurar uma litania de palavras (que se tornou depois um dístico de "Os mares do Sul"), seguindo uma cadência enfática que desde criança, nas minhas leituras de romances, tinha o hábito de assinalar, murmurando as frases que mais me obcecavam"32. De qualquer modo, já em La terra e la morte (1945) e sobretudo na colectânea póstuma Verrà la morte e avrà $i$ tuoi occhi (que passou a incluir aquela obra), o verso torna-se mais denso, a linguagem menos directa, mais ambígua, mais estranha (como que a dar voz à afirmação pavesiana de que "There is no excellent beauty that has not some strangeness"), aumentando naturalmente as dificuldades da tradução. Além disso, e como bem sabem aqueles que se dedicam ao trabalho sério de tradução (falo naturalmente de traduçóes de autor, pacientes, críticas, dialógicas, e não do que corresponde a meros serviços de tradução), o que à primeira vista parece fácil, quando assumimos apenas a posição de leitores, vai-se tornando mais e mais difícil, ao procurarmos encontrar equivalentes que, na língua alvo, funcionem de modo muito semelhante ao da língua de partida. Das edições mencionadas, a que tem o título Trabalhar cansa, tem a vantagem de ser composta por uma escolha de poemas bastante significativa, ainda que não integral, e de ser bilingue, permitindo ao leitor o cotejo do original e da tradução, com a consequente e imediata avaliação das soluções propostas. A introdução, não sendo longa, transmite ao

${ }^{31}$ Philippe Renard, Pavese, prison de l'imaginaire, lieu de l'écriture, Paris, Librairie Larousse, 1972, p. 19.

32 "O ofício de poeta", Trabalhar cansa, p. 291. 
leitor menos conhecedor do universo pavesiano a informação essencial. A edição inclui, muito correctamente, o apêndice a Lavorare stanca, composto pelos dois textos reflexivos de Pavese sobre a poesia ("Il mestiere di poeta" e "A proposito di certe poesie non ancora scritte"), como sucede nas ediçôes italianas. A edição antológica menos extensa, que referi, vem introduzida por breve, mas segura e rica nota introdutória, e é constituída por três partes, correspondendo cada a um dos três livros de poemas de Pavese, tendo o antologiadortradutor dado preferência, quantitativamente, aos poemas mais tardios de Pavese (o próprio título, O vício absurdo, é uma expressão retirada do mais emblemático e difundido poema do autor: "Verrà la morte e avrà i tuoi occhi -/questa morte che ci accompagna/dal mattino alla sera, insonne,/ sorda, come un vecchio rimorso/un vizio assurdo. (...)"). De notar, nesta antologia, a ausência do poema "I mari del Sud", o que mais acentua o que julgo ser um sinal da preferência do tradutor pela poesia do Pavese posterior ao livro Lavorare stanca. Não irei fazer um exercício da análise comparativa das traduções, embora, sobretudo quanto ao poema "Verrà la morte...", cuja tradução tem ocorrido mais vezes, isso se pudesse fazer, certamente para concluirmos, como já disse, que a poesia de Pavese tem uma natureza de certo modo peremptória, porque não deixa ao tradutor grande margem de liberdade tradutiva, sob pena de este produzir em lugar de traduções, versões (neste caso, totalmente desnecessárias). As traduções são, com efeito, muito semelhantes, com ligeiríssimas diferenças de pormenor que de modo algum alteram o sentido. Embora os poemas traduzidos tenham sempre um sabor diferente, porque a língua que neles canta é outra, os seus sons palpitam o mais discretamente possível, como se a tradução procurasse apenas a cintilação do texto, reavivando com o seu sopro as achas adormecidas, num "aceso silêncio"... 